\title{
AS INTERVENÇÕES DO PIM COMO OBJETO DE ANÁLISE
}

\author{
Fernanda Dias Almeida ${ }^{1}$ \\ Fernanda Antoniolo Hammes de Carvalho² \\ Edison Luis Devos Barlem ${ }^{3}$
}

\begin{abstract}
RESUMO
A primeira infância é uma fase da vida que necessita de cuidados essenciais para o desenvolvimento saudável da criança e que pode trazer impactos socioeconômicos à sociedade. As políticas públicas direcionadas a trabalhar esta fase da vida são imprescindíveis, pois englobam programas que estimulam atividades relacionadas ao desenvolvimento integral da criança e contribuem para a otimização do seu desenvolvimento cognitivo e socioemocional. Neste sentido, o Programa Primeira Infância Melhor (PIM), criado pelo governo do Estado do Rio Grande do Sul, é uma política de governo que atende famílias vulneráveis com gestantes e crianças de zero a três anos. Conforme estes fatores, a produção científica, que avalia as diferentes faces relacionadas ao PIM, torna-se imprescindível para a qualificação das ações envolvidas. Pela importância da temática, este artigo teve como objetivo demonstrar um panorama da produção científica nacional que tem como temática a abordagem dessa Política Pública. Para isto, foi feita uma pesquisa de caráter documental. Ao total foram encontrados dez trabalhos disponibilizados entre 2006 e 2019, contendo cinco dissertações de Mestrado, uma tese de Doutorado e quatro artigos científicos. O número reduzido de estudos mostrou-nos que ainda há uma vasta lacuna de conhecimentos sobre o Programa PIM e incentiva novos estudos que busquem compreender e melhorar a interface política pública e sociedade.
\end{abstract}

Palavras-chave: infância; mediação; desenvolvimento infantil; políticas públicas.

\section{PIM'S INTERVENTIONS AS OBJECT OF ANALYSIS}

\section{ABSTRACT}

Early childhood is a phase of life that requires essential care for the healthy development of the child and that can bring socioeconomic impacts to society. Public policies aimed at working at this stage of life are essential, as they encompass programs that stimulate activities related to the child's integral development and contribute to the optimization of their cognitive and socioemotional development. In this sense, the First Childhood Better Program (PIM), created by the State Government of Rio Grande do Sul, is a government policy that serves vulnerable families with pregnant women and children aged 0-3 years. According to these factors, the scientific production that evaluates the different faces related to the PIM, becomes essential for the qualification of the actions involved. Due to the importance of the theme, this article aimed to demonstrate an overview of national scientific production that has as its theme the approach of this Public Policy. For this, a documentary research was carried out. In total, 10 papers were found available between 2006 and 2019, containing 5 master's dissertations, 1 doctoral thesis and 4 scientific articles. The small number of studies has shown us that there is still a vast knowledge gap about the PIM program and encourages new studies that seek to understand and improve the public policy and society interface.

Keyword: childhood; mediation; child development; public policy.

Recebido em: 11/2/2020

Aceito em: $7 / 6 / 2020$

\footnotetext{
1 Autora correspondente. Faculdade de Medicina de Rio Grande (Famed-Furg). R. Gen. Osório, s/n - Centro. Rio Grande/RS, Brasil. CEP 96200-400. http://lattes.cnpq.br/8773151506765599. https://orcid.org/0000-0001-6958-3556. fediasal@gmail.com

2 IFRS - Campus Rio Grande. http://lattes.cnpq.br/0999769420370289. https://orcid.org/0000-0001-6958-3556.

3 Universidade Federal do Rio Grande - Furg. Rio Grande/RS, Brasil. http://lattes.cnpq.br/4988333912536075. https://orcid.org/0000-00016239-8657.
} 


\section{INTRODUÇÃO}

O Programa Primeira Infância Melhor (PIM) foi criado pelo governo do Estado do Rio Grande do Sul e é coordenado pela Secretaria da Saúde do Estado, tendo o apoio das Secretarias de Cultura, Educação, Trabalho e Desenvolvimento Social. Este Programa integra uma política de governo que atende famílias vulneráveis com gestantes e crianças de zero a três anos, encaminhadas, principalmente, pela Unidade Básica de Saúde da Família. As crianças já atendidas são acompanhadas até a idade máxima de seis anos (SCHNEIDER; TAMIRES; UNESCO, 2007).

O PIM foi pensado e criado por Osmar Gasparini Terra, médico brasileiro, considerado visionário quanto aos avanços das Neurociências. O Programa foi desenvolvido na Secretaria do Estado do Rio Grande do Sul no ano de 2003, visando à importância dos cuidados e estímulos necessários na primeira infância. Osmar Gasparini Terra primeiramente avaliou programas de outros países, como Cuba, com seu Programa "Educa Tu Hijo", e encontrou resultados positivos com relação ao desenvolvimento das crianças, caracterizando-o como modelo inspirador da base do PIM. O Programa cubano foi instituído no ano de 1992, com apoio do Fundo de Emergência Internacional das Nações Unidas (Unicef), e tinha um caráter intersetorial e comunitário. Em 2002, durante sua progressão, ele conseguiu englobar $70,9 \%$ da população infantil cubana de zero a seis anos de idade (SCHNEIDER; TAMIRES; UNESCO, 2007).

O Programa Primeira infância melhor foi instituído em abril de 2003 e mantido nos governos subsequentes, tornando-se Lei Estadual a partir de 2006. O Programa tem como objetivo orientar as famílias de acordo com a cultura e experiências, promovendo o desenvolvimento integral dos seus filhos desde a gestação até os seis anos de idade. O Programa foi pensado para se tornar o protagonista na Promoção de Saúde e desenvolvimento infantil. Este protagonismo se dá pois uma primeira infância saudável é um fator incisivo para o bem-estar das crianças em tenra idade, principalmente quando enfatizado nos primeiros seis anos de vida, colaborando para o seu desenvolvimento integral (SCHNEIDER; TAMIRES; UNESCO, 2007).

O PIM envolve as dimensões neurológicas, afetivas, cognitivas e sociais contextualizadas dentro do núcleo familiar e comunidade a que a criança está inserida. Estas dimensões são importantes, pois são imprescindíveis para o desenvolvimento dos cuidados e educação nos primeiros anos de vida (COSTA, 2015). Além disso, a qualificação da assistência à criança, que apresentou graves problemas no período neonatal, por meio de um atendimento multidisciplinar e periódico, e de acordo com suas demandas, é fundamental para garantir o seu desenvolvimento adequado. Com isto, há a redução ao máximo das comorbidades da criança e um suporte aos familiares.

Três eixos estruturam o programa (PIM): o grupo familiar envolvido, a comunidade e a intersetorialidade. A família constitui um dos eixos por ser o núcleo na configuração do indivíduo, e a comunidade por ser um espaço fundamental de potencialidades, recursos materiais, humanos e diversidade de instituições. Além disso, a comunidade também apresenta um papel de divulgação, apoio às medidas educativas e de saúde, vislumbrando o desenvolvimento da criança como um todo. A intersetorialidade, que também integra um destes eixos, engloba a constatação e a articulação de todos os 
setores envolvidos no desenvolvimento infantil (SCHNEIDER; TAMIRES; UNESCO, 2007). Ainda, o Programa tem um embasamento teórico nos pressupostos de Vygotsky, Piaget, Bowlby, Winnicot e Brunner e nas Neurociências, contando com avaliações trimestrais das famílias por intermédio da tabela de "Diagnóstico Inicial do Desenvolvimento Infantil" (DA COSTA, 2015).

Os visitadores do PIM atuam como mediadores no processo de interação com as famílias, seja em suas residências ou em atividades comunitárias, orientando com relação à saúde da criança e dos familiares. Estas orientações englobam diferentes aspectos de saúde, como alimentação, higiene, desenvolvimento cognitivo, neuropsicomotor, comportamental e emocional. O papel dos visitadores transpõe a ideia de orientações simplificadas, pois o programa também realiza avaliações periódicas dos visitadores e das crianças. Os visitadores utilizam o "Diagnóstico Inicial do Desenvolvimento Infantil" constituído de tabelas que apontam competências e habilidades nas quais as crianças devem se encontrar conforme a idade. Essas avaliações acontecem no período indicado na tabela, isto é, após a criança completar o período indicado. As ações dos visitadores são orientadas por monitores que coordenam, em média, oito visitadores, além de contarem com o apoio dos gestores do programa e dos serviços do município para ações de educação permanente. As avaliações dos visitadores são realizadas semanalmente em conjunto aos encontros com o grupo da área de atuação e o monitor. Estes encontros têm por finalidade articular ações e sanar dúvidas com o monitor e com outros profissionais, caso seja necessário e solicitado pelos visitadores. Cada visitador é responsável por cerca de 17 famílias, preferencialmente no mesmo bairro. As visitas têm, em média, 45 minutos de duração e são realizadas semanalmente em horário fixo. Estas visitas ocorrem com o objetivo de passar conhecimentos às famílias sobre saúde, assistência social e atividades para os responsáveis desenvolverem com as crianças. Além disso, destacamos que a capacitação inicial do visitador é de aproximadamente 60 horas com base em 3 pilares básicos: saúde, educação e assistência social (VERCH, 2017).

Recentemente, em outubro de 2019, o PIM recebeu o Prêmio Fundação Banco do Brasil de Tecnologia Social. O prêmio reconhece e valoriza ações que promovam o desenvolvimento integral das crianças e que estimulem o vínculo familiar e o exercício da parentalidade. Devido ao exposto e à necessidade de aprofundar conhecimentos acerca dessa política pública, este trabalho teve como objetivo realizar um estudo sistemático denominado "estado da arte", tendo como foco a produção científica nacional que abarque o PIM. Neste tipo de estudo, segundo Botero (2000), é feito o diagnóstico, sendo definido como o estado atual do conhecimento, possibilitando analisar o que foi gerado de conhecimento sobre determinado tema e indicar lacunas existentes.

\section{MÉTODO}

Trata-se de uma pesquisa documental, a qual oportuniza explorar fontes diversas como pareceres, atas, relatórios, notas, diários, projetos de lei, ofícios, discursos, informativos, depoimentos orais ou escritos, certidões, correspondências e demais documentos informativos arquivados em instituições distintas (SANTOS, 2000). A busca foi realizada nas bases Lilacs, Pubmed e Scielo. As palavras chaves foram: "PIM", "visitador", "desenvolvimento infantil", "Programa Primeira Infância Melhor" e "Política Pú- 
blica para a Primeira Infância". Os objetos da busca foram dissertações, teses e artigos, produzidos com a temática, que haviam sido produzidos e publicados entre os anos de 2006 e 2018.

\section{ANÁLISE E DISCUSSÃO DOS DADOS}

Após a busca foram encontrados dez trabalhos, disponibilizados entre 2006 e 2018, sendo cinco dissertações de Mestrado, uma tese de Doutorado e quatro artigos. Nos Quadros 1 e 2 são apresentados os trabalhos que englobaram esta revisão.

De um ponto de vista temporal, podemos perceber que, apesar de o PIM ter sido instaurado em 2003, as produções tiveram início apenas em 2010, havendo uma produtividade maior no ano de 2015 (dois artigos, uma tese e duas dissertações). Ainda no que diz respeito a dissertações e teses, é perceptível que a produção majoritariamente ocorreu no campo da educação (Quadro 1).

Quadro 1 - Dissertações e tese com a temática sobre o PIM

\begin{tabular}{|c|c|c|c|c|}
\hline AUTOR & TíTULO & $\begin{array}{c}\text { ÁREA DE } \\
\text { CONCENTRAÇÃo }\end{array}$ & INSTITUIÇÃO & ANO \\
\hline $\begin{array}{l}\text { Carolina } \\
\text { de V. } \\
\text { Drugg }\end{array}$ & $\begin{array}{c}\text { Formação e desempenho do } \\
\text { visitador na prática socioeducativa } \\
\text { do Programa Primeira Infância } \\
\text { Melhor }\end{array}$ & $\begin{array}{l}\text { Programa de Pós- } \\
\text { Graduação em } \\
\text { Educação }\end{array}$ & $\begin{array}{c}\text { Pontifícia } \\
\text { Universidade } \\
\text { Católica do Rio } \\
\text { Grande do Sul } \\
\end{array}$ & 2011 \\
\hline $\begin{array}{l}\text { Tatiana } \\
\text { Afonso da } \\
\text { Costa }\end{array}$ & $\begin{array}{l}\text { Os visitadores do PIM e } \\
\text { conhecimentos da Neurociência: } \\
\text { uma articulação necessária. }\end{array}$ & $\begin{array}{l}\text { Educação em } \\
\text { Ciências, Química } \\
\text { da Vida e Saúde }\end{array}$ & $\begin{array}{c}\text { Universidade } \\
\text { Federal do Rio } \\
\text { Grande }\end{array}$ & 2015 \\
\hline $\begin{array}{l}\text { Scheila } \\
\text { Paula } \\
\text { Zorzan }\end{array}$ & $\begin{array}{c}\text { Gestão de qualidade em } \\
\text { educação: a experiência do } \\
\text { Programa Primeira Infância } \\
\text { Melhor } \\
\end{array}$ & $\begin{array}{l}\text { Programa de Pós- } \\
\text { Graduação em } \\
\text { Educação }\end{array}$ & $\begin{array}{c}\text { Pontifícia } \\
\text { Universidade } \\
\text { Católica do Rio } \\
\text { Grande do Sul } \\
\end{array}$ & 2011 \\
\hline $\begin{array}{l}\text { Karine Isis } \\
\text { Bernardes }\end{array}$ & $\begin{array}{l}\text { Avaliação do Primeira Infância } \\
\text { Melhor através de estudos } \\
\text { de casos: o encontro entre a } \\
\text { educação formal e não-formal }\end{array}$ & $\begin{array}{l}\text { Programa de Pós- } \\
\text { Graduação em } \\
\text { Educação }\end{array}$ & $\begin{array}{c}\text { Pontifícia } \\
\text { Universidade } \\
\text { Católica do Rio } \\
\text { Grande do Sul } \\
\end{array}$ & 2010 \\
\hline $\begin{array}{l}\text { Liése } \\
\text { Gomes } \\
\text { Serpa }\end{array}$ & $\begin{array}{l}\text { Avaliação do acesso à política } \\
\text { primeira infância melhor no Rio } \\
\text { Grande do Sul como estratégia } \\
\text { para equidade às crianças, } \\
\text { gestantes e suas famílias } \\
\end{array}$ & $\begin{array}{l}\text { Programa de Pós- } \\
\text { Graduação em } \\
\text { Saúde Coletiva }\end{array}$ & $\begin{array}{l}\text { Universidade } \\
\text { Federal do Rio } \\
\text { Grande do Sul }\end{array}$ & 2015 \\
\hline $\begin{array}{l}\text { Ana Lucia } \\
\text { Pires } \\
\text { Afonso da } \\
\text { Costa* }\end{array}$ & $\begin{array}{l}\text { Análise Documental: uma } \\
\text { alternativa para otimização do } \\
\text { Programa Primeira Infância } \\
\text { Melhor }\end{array}$ & $\begin{array}{l}\text { Educação em } \\
\text { Ciências, Química } \\
\text { da Vida e Saúde }\end{array}$ & $\begin{array}{l}\text { Universidade } \\
\text { Federal do Rio } \\
\text { Grande }\end{array}$ & 2015 \\
\hline
\end{tabular}

* Tese de Doutorado.

Fonte: Os autores.

Dos trabalhados analisados apenas duas dissertações apresentaram como escopo os visitadores do PIM. Dentre elas o estudo de Drugg (2011), intitulado Formação e desempenho do visitador na Prática Socioeducativa do Programa Primeira Infância Melhor, que objetivou investigar as necessidades de formação inicial e continuada do visitador 
no PIM, considerando seu desempenho na orientação das famílias atendidas. O estudo foi realizado por meio de um levantamento junto a 121 visitadores de 17 municípios do Estado do Rio Grande do Sul. Os dados foram coletados mediante questionário com perguntas abertas e fechadas. Na análise dos dados foi utilizada a escala de Lickert para quantificação das perguntas fechadas e a análise de discurso para as perguntas abertas. Os achados do estudo revelaram que os visitadores possuem um bom entendimento no seu papel na estrutura do Programa, entretanto apontaram algumas inadequações importantes no modo como desenvolvem o seu trabalho.

A autora indica que, devido à complexidade metodológica do PIM e à inexperiência dos profissionais quanto ao programa, poderá haver a promoção de insegurança nos gerenciadores dos municípios, o que pode comprometer a qualificação inicial dos visitadores. Ainda, a autora ressalva a importância de serem trabalhados conteúdos que estejam adequados à realidade local, auxiliando o visitador a compreender seu papel na prática. Outro ponto abordado, que é crucial para a adequação dos profissionais à filosofia do Programa e à metodologia de atendimento, está na desconstrução dos conceitos de família ideal por meio de uma aproximação das realidades assistidas. Isto se dá porque o visitador e sua prática requerem uma compreensão do seu próprio papel e de sua representação e responsabilidade estabelecidas com as famílias. O visitador é considerado, portanto, a figura central do PIM, e sua interferência se propõe a atribuir e instituir uma prática de educação social. Esta prática, trazida pela autora, denota uma visão educacional como de um educador que busca uma aproximação com o educando, para que possa compreender o seu cotidiano e encontrar caminhos para promover a conscientização. Esta abordagem seria pela motivação dos educandos, para que participem ativamente do seu próprio desenvolvimento e reconheçam o seu protagonismo perante a vida.

Para que o visitador consiga portar as ferramentas necessárias para interagir ativamente com as famílias são necessários investimentos para formação profissional. Além disso, entretanto, a autora relata que também há uma necessidade eminente de sensibilização da equipe administrativa e compreensão sobre o significado de um programa voltado às mudanças sociais. A proposta transformadora que objetiva o PIM acaba demandando uma ressignificação da prática educativa e o conhecimento de que as famílias são compostas por universos e significados distintos. No que se refere ao visitador deve-se, todavia, tomar um lugar de escuta e investigar este universo para que possa também compreender as expectativas e motivações relacionadas a sua proposta de trabalho.

Como conclusão da dissertação, a autora indica a necessidade de articular à capacitação e ao exercício de acompanhar o trabalho de visitadores na prática. Segundo a pesquisadora, isso passa a garantir a supervisão do desempenho e a elaboração de um diagnóstico que fundamente os planos de capacitação.

Seguindo esta mesma linha de investigação, o estudo de Costa (2015), intitulado "Os visitadores do Programa Primeira Infância Melhor (PIM) e conhecimentos da neurociência: uma articulação necessária", teve como objetivo identificar como os documentos norteadores e os saberes dos visitadores do PIM/Pelotas podem influenciar no desenvolvimento das atividades com as famílias assistidas. O trabalho empregou um 
método misto, envolvendo pesquisa documental e estudo empírico junto a 43 visitadores do PIM/Pelotas-RS, ocorrendo em quatro etapas. Na primeira etapa foram analisados os materiais utilizados pelos visitadores (tabelas de ganhos e guias dos visitadores - da gestante e da família) com a intenção de verificar quais áreas do conhecimento são contempladas. Na segunda, foi aplicado um questionário semiaberto com todos os visitadores ingressos no programa no período de janeiro de 2014 até a data da coleta de dados. Na terceira etapa o Grupo de Pesquisa em Neurociência e Educação (GPNEd) promoveu um curso para todos os visitadores do PIM. Este curso teve como foco o desenvolvimento de tópicos que apareceram como frágeis ou insuficientes nos questionários, relacionados aos conhecimentos de neurociência e sua aplicação nas atividades usadas pelos visitadores. Na última fase foi realizada a replicação do questionário semiaberto pós-curso, objetivando a verificação de possíveis mudanças na atuação dos visitadores.

Os resultados do estudo revelaram que os documentos analisados (guia dos visitadores - da gestante e da família) apresentam orientações relacionadas ao cuidado da família, mas orientações de "como" fazer a intervenção junto as famílias são inexistentes. Quanto aos saberes dos visitadores, após curso de neurociência, houveram alterações conceituais positivas acerca da aprendizagem, e, além disso, eles passaram a reconhecer a insuficiência de seus saberes. Fato importante abordado pela pesquisadora, pois reconhecer o desconhecimento e a necessidade de melhoria torna-se o primeiro passo para a busca por novos saberes e aplicações. A pesquisadora conclui seu trabalho preconizando que há necessidade de maiores investimentos na educação permanente dos visitadores, e aponta como necessário o fornecimento de materiais que melhor norteiem a ação junto as famílias.

A pesquisa desenvolvida por Zorzan (2011), intitulada "Gestão de qualidade em educação: a experiência do Programa Primeira Infância Melhor", objetivou investigar os aspectos diferenciais no perfil dos gestores municipais no PIM no caso de um município com histórico satisfatório de qualidade de execução do referido Programa, bem como no caso de um município com histórico insatisfatório de execução do mesmo. A análise dos dados demonstrou que há uma relação de maior identificação com a causa do PIM por parte dos gestores do município considerado de qualidade satisfatória na execução do Programa. Além disso, foi evidenciada que há uma tendência para aspectos comuns entre gestores pertencentes a um mesmo munícipio. Outro achado foi a influência da forma como os visitadores são escolhidos pelos municípios. O município considerado satisfatório escolhe ou indica os profissionais de acordo com a sua formação ou afinidade às demandas; isso auxilia na identificação do profissional com a causa do PIM. Ainda, há uma importância no respaldo dado pela Prefeitura para as tomadas de decisão da equipe, o que também demonstrou auxiliar na execução satisfatória do PIM. Diante do exposto, a pesquisadora retrata a relevância da manutenção do investimento na sensibilização e preparação dos gestores municipais do PIM (ZORZAN, 2011).

Outra dissertação incorporada foi a de Bernardes (2010), intitulada "Avaliação do Programa Primeira Infância Melhor através de estudos de casos: o encontro entre a educação formal e não-formal", e que ocorreu no munícipio de Dois Irmãos. Neste trabalho o objetivo foi investigar os impactos do Programa Primeira Infância no primeiro ano de 
escolarização por meio da comparação entre três crianças atendidas pelo PIM e três crianças que não receberam nenhum tipo de atendimento na educação infantil. Como metodologia foi realizado um estudo de caso com abordagem qualitativa. As famílias das seis crianças envolvidas constituíram parte da amostra. Paralelamente a este estudo foi realizada, também, uma pesquisa documental que teve como fonte diferentes documentos institucionais e depoimentos registrados no instrumento de acompanhamento de ganhos do desenvolvimento infantil do Programa.

A pesquisa analisou o envolvimento dos pais/cuidadores na rotina escolar, verificando os ganhos de todas as crianças pesquisadas nas dimensões socioafetiva, motora, cognitiva e de linguagem. Ainda, foram abordadas as reflexões sobre diferentes pontos, como o relacionamento das crianças avaliadas com professores e demais colegas, 0 processo de adaptação à instituição formal destas crianças e a importância de políticas públicas no atendimento às crianças nos seus primeiros anos de vida. Os achados da pesquisa mostraram que as crianças participantes do PIM apresentaram melhor desenvolvimento e adaptação no primeiro ano de escolarização. Além disso, as suas famílias demonstraram melhor entendimento no desenvolvimento de seus filhos e uma maior participação na rotina escolar, qualificando o vínculo e potencializando a autonomia e autoestima das crianças. Como conclusão, a pesquisadora demonstra a necessidade de maior integração entre o PIM e a escola para que os ganhos alcançados durante o acompanhamento do Programa perdurem por todo período escolar.

A dissertação realizada por Serpa (2015), com o título "Avaliação do acesso à política Primeira Infância Melhor no Rio Grande do Sul como estratégia para equidade às crianças, gestantes e suas famílias", abordou a cobertura do PIM como indicador da capacidade política instituída e a produção de equidade na atenção à saúde. $O$ estudo foi desenvolvido em duas fases e teve um delineamento misto, de caráter qualitativo e quantitativo. No primeiro momento foi realizada uma revisão sistemática que analisou os objetivos, população-alvo e estratégia de introdução do PIM via análise dos documentos do Programa. Num segundo momento houve a descrição e comparação da cobertura estadual do PIM. A comparação foi analisada mediante exame de desigualdades regionais, socioeconômicas, étnico raciais e de faixa etária (SERPA, 2015).

A revisão sistemática documental identificou 15 documentos oficiais do PIM: duas leis, dois decretos, sete portarias e quatro manuais operacionais. A análise do conteúdo desses documentos mostra que o objetivo central do PIM é promover o desenvolvimento integral das crianças por meio da orientação à família em visitação domiciliar, respeitando suas culturas e experiências. A população-alvo é delimitada pelo ciclo da vida (gestação e primeira infância) e tem abrangência estadual, mas prioriza famílias e municípios em vulnerabilidade social.

A análise da cobertura do PIM mostrou que até 2015 o Programa estava em 268 dos 497 municípios do Rio Grande do Sul. Ainda, as coberturas estavam aumentando gradativamente e alcançando $7 \%$ em crianças e $5 \%$ em gestantes. Na aplicação do exame foi possível identificar que há desigualdades socioeconômicas e macrorregionais relacionadas à alta cobertura nos municípios com maior vulnerabilidade social da população (cobertura $=40,2 \%$ ) e nas macrorregiões missioneira e norte (cobertura $=20 \%$ ). Foi visto também que a região metropolitana foi a que deteve menor cobertura (cobertura 
$<2,0 \%)$. Quanto às questões étnico-raciais, o estudo mostrou que em 2013 a cobertura do PIM com crianças foi de $2 \%$ entre as de cor amarela, $4 \%$ nas pretas, $5 \%$ nas brancas e pardas e $13 \%$ nas indígenas. Em relação à vulnerabilidade familiar, a pesquisa demonstrou que cerca de $90 \%$ das famílias vive com mais de meio salário mínimo per capita, mas $55 \%$ vivem em comunidades sem esgoto sanitário, $70 \%$ sem coleta de lixo e $10 \%$ sem água encanada. Ademais, foi observado que a porcentagem de crianças que ingressou no PIM antes de três anos de idade aumentou de 60\% em 2003 para 90\% em 2013. Diante dos resultados e discussões abordados no estudo, a pesquisadora conclui que, embora o PIM tenha sido concebido como uma política universalista para o desenvolvimento da criança, ele tem sido posto como uma política focal, atendendo, predominantemente, famílias e municípios em situação de vulnerabilidade social. Isto acaba sendo direcionado à formação de uma barreira para o alcance da equidade, principalmente quando há uma taxa de 93,4\% de crianças excluídas do Programa. Isto não desmerece o fato de que as famílias potencialmente mais vulneráveis parecem receber uma maior intensidade de atenção. Segundo a pesquisadora, entretanto, uma alternativa para o alcance da equidade é a integração com outras políticas ou programas, como o Programa Agente Comunitários de Saúde (Pacs) e a Estratégia Saúde da Família (ESF).

Em nossa revisão foi encontrada apenas uma tese sobre a temática PIM (Quadro 1). A tese de Doutorado teve como título "Análise documental: uma alternativa para otimização do Programa Primeira Infância Melhor", e foi desenvolvida em um Programa de Pós-Graduação também da área de educação. Costa (2015) investigou diferentes perspectivas do PIM, como a eficácia da aplicação dos instrumentos utilizados pelo Programa na intervenção dos visitadores junto as famílias acompanhadas; o perfil da população atendida no munícipios de Pelotas; se o perfil da população atendida correspondia ao perfil pretendido pelo programa; o número de fichas com registros observacionais; e o preenchimento das fichas, tendo como referência a aproximação entre os registros observacionais e os aspectos de desenvolvimento apontados na avaliação por faixa etária. Além disso, a pesquisadora também identificou possíveis dificuldades dos visitadores no preenchimento dos documentos. O corpus do estudo englobou os registros contidos nos formulários preenchidos pelos visitadores do PIM, caracterizando uma pesquisa documental. A análise dos dados teve um caráter quantitativo e qualitativo, com a descrição dos dados quantitativos e análise de conteúdo, respectivamente (COSTA, 2015).

Os resultados da tese confirmam o pressuposto de que os documentos são insuficientemente claros, determinando observações breves, pouco aprofundadas e limitadas. Em razão disso, a pesquisadora sugere modificações pontuais nos documentos preenchidos pelos visitadores, a fim de melhorar a interpretação dos dados e facilitar o preenchimento correto. Dentre estas modificações foi sugerido que algumas questões sejam realocadas, que algumas perguntas sejam menos redundantes e outras sejam mais pontuais. Com isto, esta reestruturação facilitaria os processos de mediação, intervenção e monitoramento realizado, em especial, pelo visitador. Apesar de não ter constituído o objetivo da pesquisa, a análise documental apontou para a necessidade do reforço da educação permanente do visitador e dos monitores. Isto deverá ser realizado no sentido de torná-los observadores sistemáticos e críticos. 
No que se refere à produção de artigos científicos, foram encontrados quatro artigos, posto que nenhum deles deriva das dissertações e da tese que tiveram a temática PIM. Três trabalhos foram publicados em revistas científicas ligadas à área da saúde (Quadro 2).

O artigo intitulado "O Programa Primeira Infância Melhor no Rio Grande do Sul: uma avaliação à luz da abordagem das capacitações", de Porsse et al. (2012), analisou o Programa Primeira Infância Melhor (PIM) e verificou se tal política pública está baseada na abordagem das capacitações. O referido trabalho utilizou informações referentes ao PIM para identificar quais os funcionamentos que o Programa insere em suas linhas de ação e o que alcançam com a execução dessas ações (PORSSE et al., 2012). Mediante os resultados, os autores concluíram que o Programa é orientado pela perspectiva direcionada às suas linhas de ação, contribuindo para a expansão das capacitações humanas e para a redução da pobreza. Ademais, contém como alicerces básicos a comunidade e a família, notadamente as mães, como os agentes cruciais na promoção do desenvolvimento e da saúde.

O artigo desenvolvido por Kaiser e Freitas (2010), denominado "Programa Primeira Infância Melhor: percepções do visitador", objetivou conhecer as percepções do visitador no contexto de suas atividades no Programa, suas potencialidades e limitações nas atividades desempenhadas pelo mesmo. $O$ estudo envolveu uma abordagem metodológica qualitativo-exploratório-descritiva. A análise dos dados foi realizada com base na técnica de análise de conteúdo. A coleta de dados foi realizada em 2008, com 256 visitadores (KAISER; FREITAS, 2010). Os participantes do estudo assinaram o Termo de Consentimento Livre e Esclarecido nas capacitações do Programa, juntamente com o instrumento de pesquisa preenchido. O estudo englobou 38 dentre os 217 municípios do Estado do Rio Grande do Sul, Brasil, que estavam com o PIM estabelecido. Após aplicação do questionário os autores contribuíram para a seleção e capacitação de visitadores, qualificando-os e adequando suas atuações nas ações comunitárias no Programa Primeira Infância Melhor.

"Educação, Saúde e Trabalho: o Programa Primeira Infância Melhor - PIM - em São Lourenço do Sul/RS", de autoria de Timm et al. (2016), revisou elementos do PIM. $\mathrm{O}$ artigo consistiu em avaliar a importância e a relação do Programa com a promoção da saúde e da educação e seu contexto histórico/metodológico no município de São Lourenço do Sul-RS. Foi realizado um estudo bibliográfico qualitativo, tendo sido feita uma reunião de guias de orientação do programa, artigos e dissertações sobre o tema. Além do estudo bibliográfico, foram entrevistadas três visitadoras que atuam no referido serviço. As análises dos dados foram realizadas com base na Análise de Conteúdo. Como conclusão, os autores discutem que o PIM é de extrema importância para o município em análise, levando informações e auxiliando nos cuidados para com as gestantes e no desenvolvimento integral das crianças, relacionando elementos como educação, saúde e trabalho (TIMM et al., 2016).

O artigo de Ribeiro et al. (2018), intitulado "Uma avaliação empírica do Programa Primeira Infância Melhor no Estado do Rio Grande do Sul, Brasil", teve como objetivo a investigação do efeito de um Programa de atenção primária de base familiar, o PIM, sobre a mortalidade infantil no Estado do Rio Grande do Sul. Para abranger o objetivo 
do estudo foram estimadas as trajetórias da mortalidade infantil, usando a técnica das diferenças e associando o uso de dados longitudinais para todos os municípios do Estado do Rio Grande do Sul. Nos resultados foi evidenciado que o Programa reduziu o número de óbitos por causas externas e o tempo de exposição a ele denotou um provável potencializador dos efeitos. Apesar desta contextualização, o estudo não observou as evidências de impacto sobre o número de óbitos por causas gerais. Diante dos resultados encontrados foi notável a congruência dos achados com a natureza do Programa, melhorando a saúde tanto dos adultos quanto das crianças. Além disso, o estudo demonstrou que o Programa Primeira Infância Melhor apresenta eficácia na diminuição do número de mortes consideradas evitáveis nos lactentes (RIBEIRO et al., 2018).

Quadro 2 - Artigos com a temática PIM

\begin{tabular}{|c|c|c|}
\hline AUTOR & TíTULO & ÁREA DE CONCENTRAÇÃO \\
\hline $\begin{array}{c}\text { PORSSE } \text { et al. } \\
(2012)\end{array}$ & $\begin{array}{c}\text { O Programa Primeira Infância Melhor no } \\
\text { Rio Grande do Sul: Uma avaliação à luz da } \\
\text { abordagem das capacitações. }\end{array}$ & $\begin{array}{c}\text { Centro do Estudos e } \\
\text { Pesquisas Econômica }\end{array}$ \\
\hline $\begin{array}{c}\text { TIMM et al. } \\
(2016)\end{array}$ & $\begin{array}{c}\text { Educação, Saúde e Trabalho: o Programa } \\
\text { Primeira Infância Melhor - PIM em São } \\
\text { Lourenço do Sul/RS }\end{array}$ & Educação, Saúde e Trabalho \\
\hline $\begin{array}{c}\text { RIBEIRO et al. } \\
(2018)\end{array}$ & $\begin{array}{c}\text { Uma avaliação empírica do Programa } \\
\text { Primeira Infância Melhor no Estado do Rio } \\
\text { Grande do Sul, Brasil }\end{array}$ & Saúde Pública \\
\hline KAISER; & $\begin{array}{c}\text { Programa Primeira Infância Melhor: } \\
\text { percepções do visitador }\end{array}$ & Ciência, Cuidado e Saúde \\
\hline
\end{tabular}

Fonte: Os autores.

Como é possível perceber, dados os objetivos das pesquisas e os artigos produzidos, as produções científicas inserem-se na ideia de avaliação da política pública, que, feita a posteriori, pode fornecer informações sobre os efeitos produzidos na sociedade (ARRETCHE, 2003). Essa inserção dos trabalhos aqui apresentados pode ser concebida como um movimento esperado, pois, para Arretche (2003, p. 8), “[...] o conteúdo da produção acadêmica (teses, artigos e pesquisas) tem sido, em boa medida, a avaliação dos resultados alcançados pelas políticas em voga ou a atualização da informação existente sobre programas já consolidados".

Nesse sentido, os trabalhos analisados apontam não só ganhos diante da aplicação da política pública, no caso PIM, mas também lacunas e insuficiências quando considerados os objetivos do referido Programa. A partir da análise feita é possível apontar, também, que a totalidade das dissertações e tese foi produzida em instituições no Estado do RS, revelando um interesse específico quando considerada a política pública estadual. Apesar do interesse local, conforme Osmar Terra (2016), a avaliação e monitoramento de políticas públicas regionais que almejem a atenção ao desenvolvimento infantil são essenciais para embasar um Programa nacional como o Criança Feliz (TERRA, 2016). É possível inferir, no entanto, a ausência de dissertações, teses e artigos que tenham como objeto de investigação o impacto das ações do PIM junto a pacientes Egressos de Unidade de Terapia Intensiva Neonatal. Esse achado reitera a afirmação de Braga e Sena (2012), que destacam que o desenvolvimento de pesquisas que permitam 
a visibilidade, a longo prazo, do impacto do cuidado prestado ao recém-nascido, é essencial após a alta hospitalar, pois a assistência agrega qualidade de vida para a criança e sua família.

Ainda, com os estudos abordados podemos destacar dois pontos que detiveram maiores observações nos estudos: a necessidade constante de qualificação dos visitadores e o engajamento familiar. Estes dois pontos, em conjunto com a gerência satisfatória e entendimento da importância do PIM para a equidade social no munícipio, parecem ser cruciais para a plena execução do Programa e alcance dos objetivos propostos. As implicações e reflexões dos estudos são plausíveis de serem repensadas pelos órgãos gestores e visitadores do PIM. Acreditamos que estes sejam trabalhos que deveriam ter uma maior divulgação dentro do núcleo do PIM, pois estas ações ajudariam nas reflexões sobre pontos cruciais que possam ser melhorados e repensados na execução do Programa. Salientamos, ainda, que, apesar da maioria das pesquisas sugerirem pontos críticos e que devem ser melhorados, poucas trazem estes pontos de forma prática e objetiva, a fim de elucidar sugestões para modificações e qualificação na execução do Programa. Este ponto é crucial para promover as implicações e importância da interface pesquisa-sociedade.

\section{CONSIDERAÇÕES FINAIS}

Com referência aos achados da pesquisa, é perceptível que a abordagem da temática PIM pela produção científica nacional é escassa, com lacunas a serem preenchidas. Grande parte dos estudos estão situados nas áreas de educação, o que demonstra um grande interesse da área em compreender os paradigmas vivenciados pelo programa e seus desafios. A aplicação da área da saúde demonstrou, entretanto, escassez de trabalhos que poderiam embasar próximos passos a serem atingidos dentro do Programa, sendo este um ponto a ser refletido e modificado. Ademais, as considerações dos trabalhos mostraram ser de extrema importância para a observação e a criticidade sobre a atual situação de instalação do PIM. Há, contudo, ainda, diferentes lacunas e perguntas a serem preenchidas sobre a execução do Programa.

Dentre as lacunas existentes indicamos a ausência de exploração da relação do PIM e a abordagem com pacientes egressos de Unidade de Terapia Intensiva Neonatal. Além disso, indicamos a necessidade de ampliar este panorama, pois o entendimento sobre esta realidade ainda parece obscuro ante as outras já abordadas.

Importa destacar que existe uma sequência de etapas envolvidas na assistência à criança egressa da Unidade de Terapia Intensiva (UTI). O acompanhamento e monitoramento do desenvolvimento humano, nesse caso, deve se dar de forma específica, atendendo às demandas. Pesquisas nessa área abrem caminho para críticas e reflexões acerca do potencial de intervenção de uma política pública como o PIM diante das especificidades dessas crianças. Este tipo de abordagem acaba oferecendo subsídios para qualificar a ação pedagógica que orienta as atividades do Programa com famílias em contexto de vulnerabilidade. 
Cabe aqui retomar a função da pesquisa e da divulgação científica, que contribui para avaliar e monitorar os propósitos bem como a gestão dos programas por meio da exposição de informações, funcionando, de certo modo, como ferramentas para qualificar as políticas públicas.

\section{REFERÊNCIAS}

ARRETCHE, Marta. Dossiê agenda de pesquisas em políticas públicas. Revista Brasileira de Ciências Sociais, v. 18, n. 51, p. 7-9, 2003.

BOTERO, Consuelo Hoyos. Un modelo para una investigación documental. Guía teórico -práctica sobre construcción de estados del arte. 1. ed. Medelín. 2000. Disponível em: https://pt.scribd.com/ doc/16281901/UN-MODELO-PARA-INVESTIGACION-DOCUMENTAL-29-04-08.

BRAGA, P. P.; SENA, R. R. Estratégias para efetivar a continuidade do cuidado pós-alta ao prematuro: revisão integrativa. Acta Paulista de Enfermagem, v. 25, n. 6, p. 975-980, 2012.

COSTA, A. L. P. A. Alternativa para otimização do programa primeira infância melhor: uma análise documental. 2015. Universidade Federal do Rio Grande, 2015. Disponível em: https://sistemas.furg.br/sistemas/sab/arquivos/bdtd/0000010928.pdf

DA COSTA, Tatiana Afonso. Os visitadores do programa primeira infância melhor e conhecimentos da neurociencia: uma articulação necessária. Rio Grande: Universidade Federal do Rio Grande, 2015. Disponível em: https://sistemas.furg.br/sistemas/sab/arquivos/bdtd/0000010715.pdf

DRUGG, Carolina de V. Formação e desempenho do visitador na prática socioeducativa do Programa Primeira Infância Melhor. Porto Alegre: Pontifícia Universidade Católica do Rio Grande do Sul, 2011. Disponível em: http://repositorio.pucrs.br/dspace/bitstream/10923/2781/1/000430431-Texto\%2BCompleto-0. pdf

KAISER, Dagmar Elaine; FREITAS, Talita Cristiane Sutter. Programa primeira infância melhor: percepções do visitador. Ciência, Cuidado e Saúde, v. 9, n. 1, p. 81-90, 2010.

PORSSE, Melody de Campos Soares et al. O Programa Primeira Infância Melhor no Rio Grande do Sul: uma avaliação à luz da abordagem das capacitações. 2012. Disponível em: https://online.unisc.br/seer/ index.php/cepe/article/view/2642/2151. Acesso em: 23 maio 2019.

RIBEIRO, Felipe Garcia et al. An empirical assessment of the Healthy Early Childhood Program in Rio Grande do Sul State, Brazil. Cadernos de Saúde Pública, v. 34, n. 4, p. e00027917, 2018.

SANTOS, Antonio Raimundo dos. Metodologia científica - a construção do conhecimento. 8. ed. São Paulo: Lamparina, 2000.

SCHNEIDER, A.; TAMIRES, V. R.; UNESCO. Primeira infância melhor: uma inovação em política pública. 2007. Disponível em: https://unesdoc.unesco.org/ark:/48223/pf0000155250_por. Acesso em: 23 maio 2019.

SERPA, Liése Gomes. Avaliação do acesso à política primeira infância melhor no Rio Grande do Sul como estratégia para equidade às crianças, gestantes e suas famílias. 2015. Disponível em: https://lume.ufrgs. $\mathrm{br} / \mathrm{handle} / 10183 / 183707$

TERRA, Osmar. Avanços do Marco Legal da Primeira Infância. 1. ed. Brasilia. 2016. Disponível em: https:// www12.senado.leg.br/institucional/programas/primeira-infancia/pdf-arquivos/avancos-do-marco-legal-da-primeira-infancia

TIMM, Jordana et al. Educação, saúde e trabalho: o Programa Primeira Infância Melhor - PIM - em São Lourenço do Sul/RS. Política \& Trabalho, v. 5.901, n. 44, p. 227-245, 2016. Disponível em: http://search. proquest.com/docview/1870675539/

VERCH, Karine. Primeira Infância Melhor. Transformando a atenção aos primeiros anos de vida na América Latina: desafios e conquistas de uma política pública no sul do Brasil. 1. ed. Porto Alegre: Governo do Estado do Rio Grande do Sul, 2017. Disponível em: https://publications.iadb.org/pt/primeira-infancia-melhor-transformando-atencao-aos-primeiros-anos-de-vida-na-america-latina

ZORZAN, Scheila Paula. Gestão de qualidade em educação : a experiência do Programa Primeira Infância Melhor. 2011. Programa de Pós-Graduação da Faculdade de Educação da Pontifícia Universidade Católica do Rio Grande do Sul, 2011. Disponível em: http://tede2.pucrs.br/tede2/handle/tede/3726 